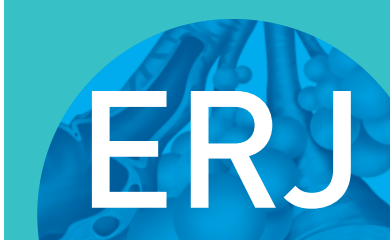

open research

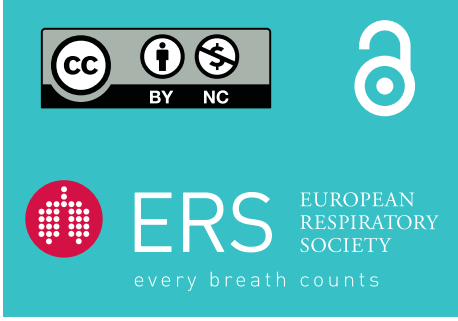

\section{Negative visual representation of chronic obstructive pulmonary disease occurs online}

\section{To the Editor:}

Visual art is a powerful, creative drive that has been used to convey ideas, express feelings and tell stories since early humans drew cave paintings. Artistic representation of disease is evident throughout history and includes portraits, medical and religious illustrations, artworks inspired by particular conditions, and even self-portraits by artists suffering from illness [1]. Notably, the Australian artist Alison Mackay recently won the Gallipoli Art Prize for her painting "Breathe". This artwork depicting nine gas masks from World Wars 1 and 2 was painted in response to the devastating Australian bushfires in early 2020, when many people were wearing breathing masks to protect themselves from the choking smoke [2].

Importantly artworks depicting illness may both reflect and influence community perceptions of disease, and therefore contribute to the perpetuation of negative or positive associations with illnesses. Negative perceptions of some illnesses, such as COPD, can lead to stigma and shame [3] and have detrimental effects upon individuals' quality of life, coping mechanisms and self-management strategies [4]. In contrast, positive immersion in the medical humanities may improve clinician empathy and communication $[5,6]$, and for patients may alter illness perception.

Whereas cardiorespiratory conditions are underrepresented in classical art forms such as poetry, film, art and storytelling [5], in recent years the internet has offered a wealth of information (of variable accuracy) on multiple health topics, including many different types of images and cartoons. As people increasingly turn to the internet for health information, this study aimed to examine the content of online images related to breathlessness for cardiorespiratory conditions in order to understand the purpose of the image and identify positive or negative depictions.

Online searches using the Google search engine were carried out in September 2019 using the search terms: "breathlessness and COPD", "breathlessness and asthma", "breathlessness and heart disease" and "breathlessness and idiopathic pulmonary fibrosis". "Breathlessness" was chosen as a search term as it is one of the most common symptoms in respiratory illnesses $[1,4,7]$. The search was limited to the first 100 images to reduce the frequency of duplicate images, including the use of stock photos. The images were captured in screenshots and the website link saved, due to the daily changes in the order and types of images displayed via Google images searches. Included images were categorised and compared by two authors (F. Berenyi and N. Smallwood) between September 2019 and January 2020, with the first 20 images reviewed together and the next 80 separately. Any discrepancies in categorisation were discussed between authors. The categories included: intended type of image, target audience and purpose of image. Image types were further categorised as: diagram, infographic, graphic, photo, cartoon, figure, table and other (e.g. presentation slide, poster, book cover and graphics interchange format (GIF)). If the image was a photo involving a person, further details were recorded including approximate age (child, young, middle-aged, elderly), gender and ethnicity. The target audience (defined as clinician, patient or either) was determined according to type of image, language used, original website source for the image and the website content.

@ERSpublications

Internet images associated with breathlessness and COPD are mainly aimed at clinicians, more likely to be negative, and are gender and culturally exclusive compared with other cardiorespiratory conditions https://bit.ly/2DMfs0r

Cite this article as: Berenyi $\mathrm{F}$, Booth $\mathrm{S}$, Spathis A. Negative visual representation of chronic obstructive pulmonary disease occurs online. ERJ Open Res 2020; 6: 00549-2020 [https://doi.org/ 10.1183/23120541.00549-2020].

Copyright $\odot$ ERS 2020. This article is open access and distributed under the terms of the Creative Commons Attribution NonCommercial Licence 4.0. 
Most online images associated with COPD were educational, including diagrams, tables and figures from journal articles, presentation slides and medical education websites, with these images being targeted towards health professionals (table 1). In contrast, the majority of images relating to asthma, heart disease or idiopathic pulmonary fibrosis were intended for a lay audience (patients or carers), with the apparent purpose being education and illness engagement. Images were sourced from a wide variety of internet sites, including patient advocacy sites, education-based sites and lung foundation websites, as well as blogs, Pinterest and slideshare sites.

Images depicting a human (in photo or cartoon form) were further categorised into those with positive or negative associations or neither. Negative images were more common in COPD than in other conditions, and included photos of people who appeared distressed while coughing, grimacing, and struggling to walk. Home oxygen therapy and cigarettes more commonly featured in relation to COPD than other illnesses. Positive images were most common in the asthma and breathlessness search, and included photos of people smiling or appearing calm, wearing active-wear, standing outside in picturesque environments, or holding inhalers while appearing relaxed. While colours can also be associated with positivity or negativity, there were no trends in either positive or negative images in terms of colour schemes for picture settings or clothes of any human subjects.

Men were the principal subjects in most online images associated with COPD (80.0\%) and heart disease (60.0\%), whereas the photos related to asthma included mostly women (71.8\%). Images related to COPD mostly depicted middle-aged or elderly people (80.0\%), whereas asthma images most commonly portrayed young people $(66.7 \%)$ and heart disease images were mainly of middle-aged individuals (46.6\%). Across all the online searches over $80 \%$ of the photos involved white people.

The English language phrase "a picture is worth a thousand words" emphasises the power of art, as a picture may convey an idea more quickly and effectively than the written word. Indeed, a visual image provides a nonverbal demonstration of an idea, emotion or story at a glance, often more effectively than written text. The addition of pictures, particularly those that are culturally relevant, to written and verbal information improves illness understanding and attention [8]. It is notable therefore that the majority of

\section{TABLE 1 Online visual representation of cardiorespiratory illnesses}

\begin{tabular}{|c|c|c|c|c|}
\hline & $\begin{array}{l}\text { COPD } \\
(n=100)\end{array}$ & $\begin{array}{l}\text { Asthma } \\
\text { (n=100) }\end{array}$ & $\begin{array}{l}\text { Heart disease } \\
\qquad(n=100)\end{array}$ & $\begin{array}{c}\text { IPF } \\
(n=100)\end{array}$ \\
\hline \multicolumn{5}{|l|}{ Image type } \\
\hline Figure/graph/diagram/table & $50(50.0)$ & $20(20.0)$ & $25(25.0)$ & 31 (31.0) \\
\hline Infographic & $3(3.0)$ & $10(10.0)$ & $7(7.0)$ & 9 (9.0) \\
\hline Cartoon & $14(14.0)$ & $2(2.0)$ & $5(5.0)$ & $2(2.0)$ \\
\hline \multicolumn{5}{|l|}{ Target audience } \\
\hline Patient & $36(36.0)$ & $65(65.0)$ & 69 (69.0) & $59(59.0)$ \\
\hline Clinician & $62(62.0)$ & $20(20.0)$ & $26(26.0)$ & $36(36.0)$ \\
\hline Either & $1(1.0)$ & 12 (12.0) & $4(4.0)$ & $5(5.0)$ \\
\hline Cigarette use in image & $4(4.0)$ & 0 & 0 & $1(1.0)$ \\
\hline $\begin{array}{l}\text { Images with depiction of human (photo or cartoon) } n \\
\text { Positive image }\end{array}$ & 20 & 39 & 32 & 24 \\
\hline $\begin{array}{l}\text { Image of person not included due to lack of relevance (research } \\
\text { presenter etc.) n }\end{array}$ & 0 & 0 & 2 & 3 \\
\hline Male gender ${ }^{\#}$ & $16(80.0)$ & $11(28.2)$ & $18(60.0)$ & $14(66.7)$ \\
\hline White ethnicity ${ }^{\#}$ & $16(80.0)$ & $35(89.7)$ & $27(90.0)$ & $21(100)$ \\
\hline Elderly & $8(40.0)$ & 0 & $8(26.7)$ & $16(76)$ \\
\hline
\end{tabular}

Data are presented $\mathrm{n}(\%)$ unless otherwise stated. Some images included pictures of males and females or people of different ages or of different racial backgrounds, meaning than one image was sometimes counted in two categories. IPF: idiopathic pulmonary fibrosis; GIF: graphics interchange format. \#: for these categories percentages are calculated using the number of images which included people in photos or cartoons for each search (not the total of 100 ). 
images identified in these online searches depicted people of white ethnicity, which does not accurately reflect the populations affected by these conditions. Furthermore, the online images related to these chronic cardiorespiratory conditions were for the most part not relevant to the affected populations.

Few previous studies have examined health-related, online art. PAIGE et al. [9] studied images associated with COPD on the website Pinterest and found that the majority of pictures contained general health information and self-management strategies. However, the most "liked" images were those with photographs, indicating photos generated higher levels of user engagement [9]. However, in contrast to our study, the photos on Pinterest were mostly of women. Their finding may be explained by the fact that Pinterest is a site marketed towards women. STELLEFSON et al. [10] explored COPD information available on YouTube. They found that there were far fewer COPD educational videos compared with other leading causes of illness, and the quality and accuracy of the content was highly variable [10]. Therefore, current research (including our study) suggests that while social media and internet resources are important tools in improving patient understanding and engagement, the information currently available may be neither relevant nor accurate. Furthermore, negative images may impact upon quality of life and perpetuate community stigma and negativity towards COPD.

Our finding that most internet images associated with breathlessness and COPD are mainly aimed at clinicians, more likely to be negative, and are gender and culturally exclusive, highlight the current online opportunities (particularly for clinicians and patient advocacy groups) to overcome negativity and stigma and better educate our patients, their caregivers and the community.

\section{Freya Berenyi ${ }^{1}$, Sara Booth $\oplus^{2}$, Anna Spathis ${ }^{2,3}$ and Natasha Smallwood $\circledast^{1,4}$}

${ }^{1}$ Dept of Respiratory and Sleep Medicine, The Royal Melbourne Hospital, Parkville, Victoria, Australia. ${ }^{2}$ Cambridge University Hospitals NHS Foundation Trust, Cambridge, UK. ${ }^{3}$ Dept of Public Health and Primary Care, University of Cambridge, Cambridge, UK. ${ }^{4}$ Dept of Medicine (Royal Melbourne Hospital), University of Melbourne, Victoria, Australia.

Correspondence: Natasha Smallwood, Dept of Medicine (Royal Melbourne Hospital), University of Melbourne, Victoria 3050, Australia. E-mail: Natasha.smallwood@mh.org.au

Received: 3 Aug 2020 | Accepted: 3 Aug 2020

Conflict of interest: None declared.

\section{References}

1 Tibayrenc M. Encyclopedia of infectious diseases: modern methodologies. Hoboken, John Wiley \& Sons, 2007.

2 Galvin, N. An accidental image for our times. The Age. www.theage.com.au/culture/art-and-design/an-accidentalimage-for-our-times-20200416-p54kez.html Date last accessed: 11 May 2020. Date last updated: 16 April 2020.

3 Johnson JL, Campbell AC, Bowers M, et al. Understanding the social consequences of chronic obstructive pulmonary disease: the effects of stigma and gender. Proc Am Thorac Soc 2007; 4: 680-682.

4 Tiemensma J, Gaab E, Voorhaar M, et al. Illness perceptions and coping determine quality of life in COPD patients. Int J Chron Obstruct Pulmon Dis 2016; 11: 2001-2007.

5 Kaptein AA, Meulenberg F, Smyth JM. A breath of fresh air: images of respiratory illness in novels, poems, films, music, and paintings. J Health Psychol 2015; 20: 246-258.

6 Kaptein AA, Meulenberg F, Smyth JM. Do art lovers make better doctors? Lancet Respir Med 2013; 1: 769-770.

7 Currow DC, Plummer JL, Crockett A, et al. A community population survey of prevalence and severity of dyspnea in adults. J Pain Symptom Manage 2009; 38: 533-545.

8 Houts PS, Doak CC, Doak LG, et al. The role of pictures in improving health communication: a review of research on attention, comprehension, recall, and adherence. Patient Educ Couns 2006; 61: 173-190.

9 Paige SR, Stellefson M, Chaney BH, et al. Pinterest as a resource for health information on chronic obstructive pulmonary disease (COPD): a social media content analysis. Am J Health Educ 2015; 46: 241-251.

10 Stellefson M, Chaney B, Ochipa K, et al. YouTube as a source of chronic obstructive pulmonary disease patient education: a social media content analysis. Chron Respir Dis 2014; 11: 61-71. 